\title{
Expression of Steroid Receptors and Cytokeratin 18 in Breast Cancer after Neoadjuvant Chemotherapy
}

Vladimir Sergeevich Chernyy*, Lydmila Fedorovna Gulyaeva and Vadim Viktorovich Kozlov

Novosibirsk, Russian Federation

\begin{abstract}
Nowadays treatment of breast cancer $(B C)$ is based on the tumor receptor status measured by the expression of ERs, PR, Her2/neu receptors. Our objective was to determine the gene expression of steroid receptors (ERa, $\mathrm{ER} \beta, \mathrm{PR}$ ), cytokeratin 18 (KRT18) in malignant breast tumors of patients untreated and treated with neoadjuvant chemotherapy (NAC). BC samples were obtained after surgery of patients who were treated in the State Regional Oncology Center (Novosibirsk) from 2011 to $2014(n=122)$. We have found that the expression of ERa in patients after NAT decreased almost three times compared to the untreated group $(p<0,05)$. To evaluate receptor status of $B C$, we used the semi-quantitative real-time RT-PCR method. It should be noted that mRNA level for ER might not always correlate with the protein level. In this regard, one of the objectives of this study was to conduct comparative analysis of immunohystochemical (IHC) results and ERa mRNA level obtained by RT-PCR. We have found that the results for ERa receptor expression measured by IHC and RTPCR match in $85.9 \%$ of cases. Besides, we determined the expression of KRT18, a marker of tumor cell proliferation, in patients under study with various tumor phenotypes. Our results also showed that the expression level of KRT18 decreased 3.2 times in tumor tissue of patients treated with NAC compared with an untreated group $(p<0,05)$. We also evaluated the expression of KRT18 depending on the tumor phenotype. We have found that patients with ER+PR+ tumors had an increased level of KRT18 in both groups under study 2.7 times on average in comparison with ERPR+/-phenotype $(p<0,05)$. Thus, selected markers can be appropriate candidates for personalized treatment of BC patients.
\end{abstract}

\section{Introduction}

Breast cancer $(\mathrm{BC})$ is the most common malignancy in women, and the second most frequent among all cancers in the general population. Over the last few years, significant progress has been made in the treatment and diagnosis of breast cancer due to intensive development of modern molecular genetic techniques. In many cases, the treatment of this disease is based on the knowledge of receptor status of the tumors, as measured by the expression of ERs, PGR, and Her2/neu receptors.

Today, an imbalance in steroid receptors ER / ER $\beta$ is one of the leading hypothesized mechanisms behind the development of breast cancer. It was shown that in normal tissue, ratio of ER $\alpha$ / ER $\beta$ is about 1: 8 ; for example, of all estrogen receptors expressed on normal mammary epithelial cells, $7-10 \%$ is ERa and $80-85 \%$ is ER $\beta$ [1]. In tumor cells, ER $\alpha$ expression is several times higher than normal, and ER $\beta$ receptor levels are reduced compared to normal tissue. The degree to which ER $\beta$ expression is reduced depends on the degree to which transformed tissue proliferates and differentiates $[1,2]$.

At present, neoadjuvant chemotherapy (NAC) is in widespread use as a preoperative treatment of breast cancer. This therapy is used for patients with locally advanced cancer (conventionally not operable) to reduce the cancer into an operable form, allowing for organ-saving surgery. The ratio of ERa to ER $\beta$, after a course of chemotherapy, is a criterion for determining whether breast cancer tumors are susceptible to NAC treatment.

Also, in recent years a lot of new molecular markers of breast cancer have been discovered, including cytokeratin 18, a filament protein of the cytoskeleton of epithelial cells, is one indicator of survival rate [3]. Cytokeratin 18 is expressed in single-layer epithelial tissues, predominantly in the cytoplasm and perinuclear regions. High levels of expression of cytokeratin 18 are found in patients with epithelial cell carcinomas, e.g., breast and prostate cancer, ovarian and gastrointestinal carcinoma [4]. It has been shown that having high levels of cytokeratin
18 after three cycles of chemotherapy was significantly correlated with low one- and two-year survival rates. Furthermore, this protein is detected in high concentrations in patients with rapidly progressing metastatic cancers [3-5].

Objective: To determine the effect of neoadjuvant chemotherapy on the genetic expression of select steroid receptors (ER $\alpha, E R \beta, P G R)$ and the KRT18 gene in malignant tumors of the breast cancer patients.

\section{Materials and Methods}

Breast tumor samples were obtained from patients who underwent

\begin{tabular}{|c|c|c|}
\hline Age of the patients & The number of patients, $\mathbf{n}$ & Percentage ratio (\%) \\
\hline Under 40 years & 4 & 8,2 \\
\hline From 41 to 50 years & 11 & 22,4 \\
\hline Over 50 years & 34 & 69,4 \\
\hline
\end{tabular}

Table 1: Distribution of patients by age in the first group.

\begin{tabular}{|c|c|c|}
\hline BC stage & The number of patients, $\mathbf{n}$ & Percentage ratio (\%) \\
\hline II A, II B & 26 & 53,1 \\
\hline III A, III B & 19 & 38,8 \\
\hline IV & 4 & 8,1 \\
\hline
\end{tabular}

Table 2: Distribution of patients by stage in the first group.

*Corresponding author: Vladimir Sergeevich Chernyy, Novosibirsk, Russian Federation, Tel: 79139368375; E-mail: vladimir.s.chernyy@gmail.com

Received July 17, 2015; Accepted September 08, 2015; Published September 12, 2015

Citation: Chernyy VS, Gulyaeva LF, Kozlov VV (2015) Expression of Steroid Receptors and Cytokeratin 18 in Breast Cancer after Neoadjuvant Chemotherapy. J Mol Biomark Diagn S2:013. doi:10.4172/2155-9929.S2-013

Copyright: (c) 2015 Chernyy VS, et al. This is an open-access article distributed under the terms of the Creative Commons Attribution License, which permits unrestricted use, distribution, and reproduction in any medium, provided the original author and source are credited 
Citation: Chernyy VS, Gulyaeva LF, Kozlov VV (2015) Expression of Steroid Receptors and Cytokeratin 18 in Breast Cancer after Neoadjuvant Chemotherapy. J Mol Biomark Diagn S2:013. doi:10.4172/2155-9929.S2-013

Page 2 of 8

\begin{tabular}{|c|c|c|}
\hline Age of the patients & The number of patients, $\mathbf{n}$ & Percentage ratio (\%) \\
\hline Under 40 years & 9 & 12,3 \\
\hline From 41 to 50 years & 24 & 32,9 \\
\hline Over 50 years & 40 & 54,8 \\
\hline
\end{tabular}

Table 3: Distribution of patients by age in the first group.

\begin{tabular}{|c|c|c|}
\hline BC stage & The number of patients, $\mathbf{n}$ & Percentage ratio (\%) \\
\hline I & 20 & 27,4 \\
\hline II A, II B & 53 & 72,6 \\
\hline
\end{tabular}

Table 4: Distribution of patients by stage in the first group.

\begin{tabular}{|c|c|c|}
\hline Gene & & Primer sequence \\
\hline \multirow[b]{2}{*}{$\beta$-actin } & Forward & 5'-GCCGAGGACTTTGATTGC-3' \\
\hline & Reverse & 5'-GTGTGGACTTGGGAGAGGA-3' \\
\hline \multirow[b]{2}{*}{ RPL } & Forward & 5'- CATTTCCGAAGCGAGTGTCT-3' \\
\hline & Reverse & 5'- GAGCGATTCCGGACTACCTT-3' \\
\hline \multirow[b]{2}{*}{ Pol II } & Forward & 5'-GCACCACGTCCAATGACAT -3' \\
\hline & Reverse & 5'-GTGCGGCTGCTTCCATAA -3' \\
\hline \multirow[b]{2}{*}{ ERa } & Forward & 5'-ATGATGAAAGGTGGGATACGA-3' \\
\hline & Reverse & 5'-АСTCTCATGTCTCCAGCAGA - 3' \\
\hline \multirow[b]{2}{*}{ ER $\beta$} & Forward & 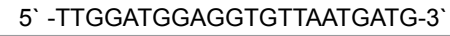 \\
\hline & Reverse & $5^{\circ}$-GAAGTAGTTGCCAGGAGCATGT-3` \\
\hline \multirow[b]{2}{*}{ PGR } & Forward & 5 -TCATTCTATTCATTATCCCTTACCA-3 \\
\hline & Reverse & $5^{\circ}$-GACTTCGTAGCCCTTCCAAAG - $3^{\circ}$ \\
\hline \multirow[b]{2}{*}{ KRT 18} & Forward & 5'- CTTGCTGCTGATGACTTTAG-3' \\
\hline & Reverse & $5^{\circ}$ - TTACTTCCTCTTCGTGGTTC-3' \\
\hline
\end{tabular}

Table 5: Sequences for primers that used in study.

surgical treatment in the thoracic department of the State Regional Oncology Center (Novosibirsk) from 2011 to 2014 ( $n=122$ ). Adjacent untransformed breast tissue served as a control. Biopsy specimens was carried out with the consent of the patients and complied with the standards set by the Ethics Committee of the Russian Federation. The medical records of patients provided data for clinical-anamnestic analysis. These data were obtained through patient questioning that was recorded on specially designed individual questionnaires, with the analysis of causes and conditions of the pathological process, age, menstrual and reproductive functions, constitutional features, and comorbidities.

\section{All patients were divided into 2 groups.}

The first group (cases): 49 samples of tumor tissue were taken from breast cancer patients aged 34 to 78 years old (mean age $56 \pm 10.4$ years), all of whom had a breast cancer diagnosis of stage $\mathrm{T}_{1-4} \mathrm{~N}_{0-1} \mathrm{M}_{0-1}$ and were treated with neoadjuvant chemotherapy (from two to four cycles with scheme «FAC» or «CAF»). Dosages for the «FAC» chemotherapy scheme are as follows: 5-fluorouracil $500 \mathrm{mg} / \mathrm{m}^{2}$, doxorubicin 50 $\mathrm{mg} / \mathrm{m}^{2}$, cyclophosphamide $500 \mathrm{mg} / \mathrm{m}^{2}$. All drugs were injected intravenously on the first day. Dosages for the «CAF» chemotherapy scheme are as follows: cyclophosphamide $100 \mathrm{mg} / \mathrm{m}^{2}$ intramuscularly from day 1 to day 14 , doxorubicin $30 \mathrm{mg} / \mathrm{m}^{2}$ intravenously on days 1 and 8,5 -fluorouracil $500 \mathrm{mg} / \mathrm{m}^{2}$ delivered intravenously on days 1 and 8. Surgery was performed 7-14 days after the end of neoadjuvant chemotherapy. Tables 1 and 2 show age and tumor stage of patients in first group.

Tissue samples extracted from patients were placed in liquid nitrogen and then stored at $-70^{\circ} \mathrm{C}$.

A second group of samples were taken from 73 patients' tumors as a control group; all patients were diagnosed with a breast cancer of stage
$\mathrm{T}_{1-3} \mathrm{~N}_{0-1} \mathrm{M}_{0}$, and all were aged between 35 and 74 years. These patients did not receive neoadjuvant chemotherapy. Their mean age was $52.5 \pm$ 10.5 years. The technique of collection and storage of the tissue samples was similar to that for the patients of the first group. Tables 3 and 4 show age and tumor stage of patients in the second group.

RNA was isolated from the tissue samples using the "RNeasy Lipid Tissue Mini Kit" (Qiagen, USA). Reverse transcription was performed using an RNA-dependent DNA polymerase "SmartTaq" (Medigen, Russia). To determine the level of gene expression, real-time PCR was performed on a thermal cycler CFX96 (Bio-Rad, USA) in the presence of SYBR Green I ("Molecular Probes", USA). To normalize the sample concentration "normalization coefficient" was used. It was calculated as the arithmetic mean of the relative amount of cDNA of RPL32, b-actin, Pol-II genes. Calculation of the relative levels of mRNA expression of the genes in question was carried out using the $\Delta \mathrm{Ct}$ method. Statistical data processing was carried out using non-parametric statistical methods

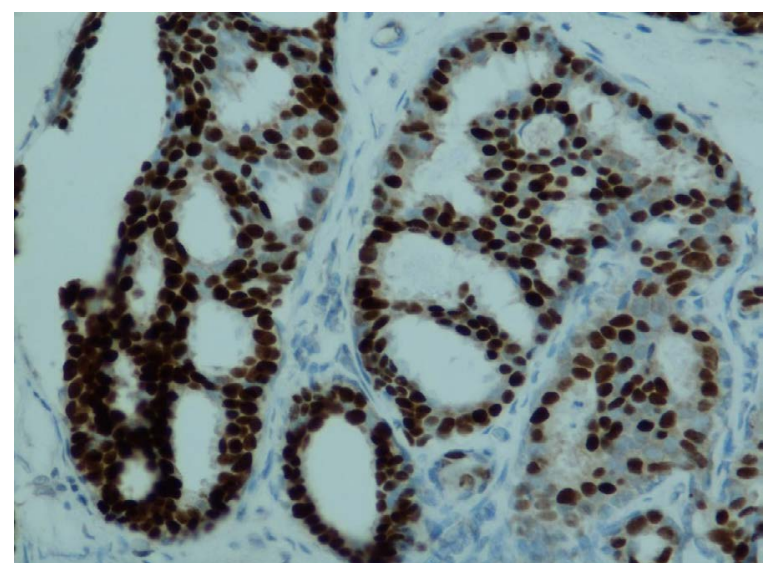

Figure 1: Expression of ER with an estimate of 7-8 points.

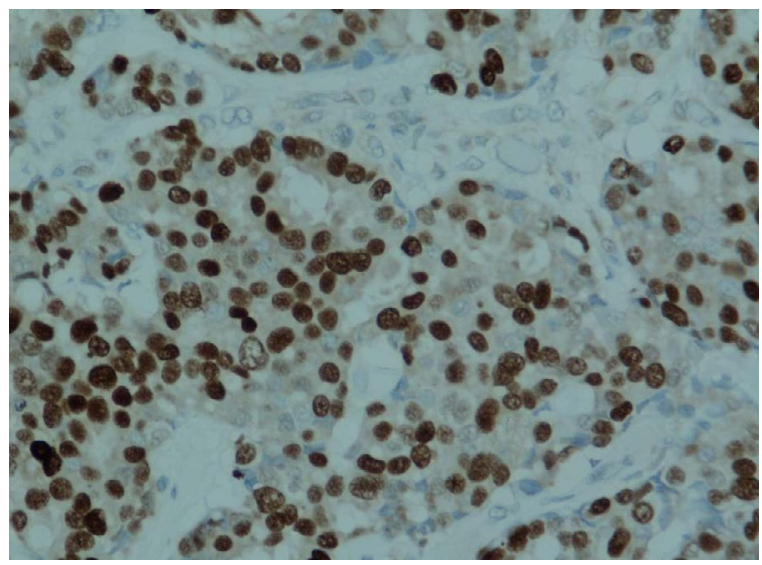

Figure 2: Expression of PGR with an estimate of 7 points.

\begin{tabular}{|c|c|c|c|c|}
\hline \multirow{2}{*}{ Receptor status } & \multicolumn{2}{|c|}{ First group, $\mathbf{n = 4 9}$} & \multicolumn{2}{c|}{ Second group, $\mathbf{n = 7 3}$} \\
\cline { 2 - 5 } & Abs & $\%$ & Abs & $\%$ \\
\hline $\mathrm{ERa}^{+} / \mathrm{ER}^{+}$ & 14 & 29 & 1 & 1 \\
\hline $\mathrm{ERa}^{+} / \mathrm{ER} \beta^{-}$ & 17 & 34 & 48 & 66 \\
\hline $\mathrm{ER \alpha}^{-} / \mathrm{ER} \beta^{+}$ & 2 & 4 & 6 & 8 \\
\hline $\mathrm{ER \alpha}^{-} / \mathrm{ER} \beta^{-}$ & 16 & 33 & 18 & 25 \\
\hline
\end{tabular}

Abs - the absolute number of patients.

Table 6: The expression of receptors ER a and ER $\beta$ in the study and control groups of patients. 
(Mann-Whitney test, Wilcoxon test). Oligonucleotide primers for the genes in question were selected using the Primer-BLAST program. Sequences for primers used in study are provided in Table 5.

Determination of ER, PGR expression in samples of malignant breast tumors by IHC analysis was performed according to standard protocols. For this study the tumor tissue was fixed in $10 \%$ buffered formalin and embedded in paraffin blocks from which histological sections of 3-4 microns thick were made. All steps of the IHC analysis (dewaxing, unmasking, incubation with primary antibodies) was performed automatically in the Bench Mark HT (Ventana) using the Rabbit monoclonal primary antibodies: Estrogen receptor (SP1 clone), Progesteron receptor (1E2 clone).

Finished preparations were studied on light microscopes NIKON - Eclipse - 50i (Japan). To determine the level of ER and PGR expression the percentage of positive cells and intensity of staining nuclei was evaluated and scored on a scale from $1+$ to $3+$ points. Points summarized according to clinical guidelines. Figures 1 and 2 shows a typical picture of ER-positive and PGR-positive breast cancer with an estimate of 7-8 points.

\section{Results and Discussion}

\section{Expression of steroid receptors}

In our work to assess receptor status of breast cancer, the qPCR method was used. Table 6 shows the results of expression of ERa and ER $\beta$ receptors in the both groups of patients. Cutoff value for estrogen receptor expression was defined as 1 . All samples with expression values greater than the threshold were considered as estrogen-positive. All samples with expression values below the threshold were considered as estrogen-negative.

Twice-positive estrogen-receptor status was observed in $29 \%$ of patients in the first group, while in the control group there were only $1 \%$ of patients with $\mathrm{ER} \alpha+/ \operatorname{ER} \beta+$. The presence of ER $\alpha+1$ $\mathrm{ER} \beta+$ status can be seen as more favorable prognostic sign, as it is characterized as a hormone-dependent tumor, which allows us to use

\begin{tabular}{|c|c|c|}
\hline mRNA level & After NAC & Without NAC \\
\hline ER $\alpha$ & $0,43 \pm 0,17^{\star}$ & $1,2 \pm 0,35^{\star}$ \\
\hline ER $\beta$ & $0,54 \pm 0,39$ & $0,47 \pm 0,28$ \\
\hline
\end{tabular}

Mean values \pm SD. * $p<0.05$

Table 7: The relative mRNA levels of ER $\alpha$ and ER $\beta$ in the control and study groups in $\mathrm{CU}$.

\begin{tabular}{|c|c|c|}
\hline mRNA level & After NAC & Without NAC \\
\hline PGR & $0,83 \pm 0,37^{*}$ & $1,05 \pm 0,25^{*}$ \\
\hline
\end{tabular}

Mean values $\pm S D$. ${ }^{*} p=0.138$

Table 8. The relative mRNA levels of PGR in the control and study groups in CU.

\begin{tabular}{|c|c|c|c|}
\hline Parameter 1 & Parameter 2 & Matching percentage & N (number of patients) \\
\hline ER (IHC) & ERa (PCR) & $85,9 \%$ & 122 \\
\hline PGR (IHC) & PGR (PCR) & $61,5 \%$ & 122 \\
\hline
\end{tabular}

Table 9: Verification data between $\mathrm{qPCR}$ and immunohistochemical analysis.

\begin{tabular}{|c|c|c|c|}
\hline Parameter 1 & Parameter 2 & Matching percentage & N (number of patients) \\
\hline ER (IHC) & ERa (PCR) & $85,9 \%$ & 122 \\
\hline PGR (IHC) & PGR (PCR) & $61,5 \%$ & 122 \\
\hline
\end{tabular}

Mean values $\pm S D$. * $p<0.05$

Table 10: Cytokeratin 18 gene expression profile comparisons in CU. hormone therapy. The low expression of ER $\beta$ prevailed in both groups, while ER $\alpha+$ / ER $\beta$ - phenotype, reflecting the "classic" imbalance of these types of receptors in the malignant "transformation of breast tissue in patients receiving therapy was significantly lower in the first group (34\% compared with $66 \%$ in the control group). These figures confirm the current literature data [6,7]. ER $\alpha$ - / ER $\beta$ - tumor phenotype was observed in $33 \%$ of the treatment group and $25 \%$ in the control. This phenotype may be indicative of the worst prognosis: patients with such tumors should be treated with chemotherapy only. The next step of our work was the calculation of the relative mRNA levels of steroid receptors, both in normal and in tumor samples based on data from the qPCR reaction. This was done using the $2^{-\Delta \mathrm{Ct}}$ formula, where $\Delta \mathrm{Ct}=$ $\left(\mathrm{Ct}_{\text {steroid.recept. }} \cdot \mathrm{Ct}_{\text {householdgene }}\right)$ tumor sample - $\left(\mathrm{Ct}_{\text {steroid Receptor. }}-\mathrm{Ct}_{\text {householdgenen }}\right)$ conventional norm. As the conventional norm sample was taken from the control group with the smallest difference of $\mathrm{Ct}_{\text {steroid. recept. }}-\mathrm{Ct}_{\text {actin }}$. Thus, the conventional level of mRNA for this sample is equal to 1 . Regarding it mRNA levels were counted in conventional units $(\mathrm{CU})$ for the remaining samples. Table 7 shows the relative mRNA levels of ERa and ER $\beta$ in the control and study groups in CU.

We found that the expression of ERa in the study group decreased almost three times compared to the control group. This is probably associated with an increase in the degree of inflammatory infiltration and fibrosis in the tumors as a sign of therapeutic pathomorphism. The average value of the relative level of mRNA in the group of patients treated with neoadjuvant therapy was $0,43 \pm 0,17 \mathrm{CU}$; in the group of patients who did not receive treatment, it was $1,2 \pm 0,35 \mathrm{CU}(\mathrm{p}<0.05)$. The expression level of ER $\beta$ in both groups did not differ; the values of the relative level of mRNA in the study group was $0,54 \pm 0,39 \mathrm{CU}$, and in the control group was $0,47 \pm 0,28 \mathrm{CU}$. In the literature, it is shown that the use of neoadjuvant chemotherapy reduces mRNA expression of both types of receptors [6,7].

In most cases, along with changes in estrogen receptor gene expression, there is also a decrease in progesterone gene expression after chemotherapy. In our study, we did not find any significant differences in the gene expression profile ratios between ER $\alpha$ and PGR in both groups (Table 8).

\section{Comparison of the expression of steroid receptors}

At present, immunohistochemical testing is the "gold standard" in characterizing ER and PGR expression in breast tissues, and it is widely used in clinical practice. To evaluate the receptor status of breast cancers, we used the qPCR method. It should be noted that the determination of receptor levels by mRNA levels (i.e. through qPCR) may not always be accurate due to post transcriptional regulation mechanisms. In this regard, one of the objectives of the study was to conduct comparative analysis of IGHI results from tumor samples with mRNA levels obtained by qPCR. Mathematical analysis was performed to determine the percentage of agreement between IHC and qPCR.

For each tumor sample threshold is selected : an ER (IHC) level greater than 3 is denoted as "1", ER (IHC) less than 3, as "0". An ERa (PCR) level $>1$ is denoted as "1", ER $\alpha$ (PCR) $<1$, as " 0 ". Then there are two vectors $\mathrm{V}$ and $\mathrm{W}$ with components 0 or 1 . Percentage match is calculated by the formula:

$\sum \mathrm{C}\left(\mathrm{V}_{\mathrm{i}} \mathrm{W}_{\mathrm{i}}\right) \times 100$

$\mathrm{i}=1 \mathrm{n}$ 


\begin{tabular}{|c|c|c|}
\hline \multirow{2}{*}{$\begin{array}{c}\text { Phenotype of the } \\
\text { tumor }\end{array}$} & \multicolumn{2}{|c|}{ mRNA level } \\
\cline { 2 - 3 } & After NAC & Without NAC \\
\hline ERa+ & $3,16 \pm 1,22(n=31)$ & $4,8 \pm 1,41(n=49)$ \\
\hline ERa- & $0,9 \pm 0,47(n=18)$ & $2,17 \pm 0,90(n=24)$ \\
\hline
\end{tabular}

Mean values \pm SD. * $p<0.05$

Table 11: The expression profile of cytokeratin 18 based on the phenotype of the tumor in CU.

$\mathrm{n}=122$, where $\mathrm{C}$, a function of two arguments, is defined as follows: $\mathrm{C}\left(\mathrm{V}_{\mathrm{i}} \mathrm{W}_{\mathrm{i}}\right)=1$, if $\mathrm{V}_{\mathrm{i}}=\mathrm{W}_{\mathrm{i}}$, and $\mathrm{C}\left(\mathrm{V}_{\mathrm{i}} \mathrm{W}_{\mathrm{i}}\right)=0$, if $\mathrm{V}_{\mathrm{i}} \neq \mathrm{W}_{\mathrm{i}}$

Thus, we obtained verification data between qPCR and immunohistochemical analysis (Table 9).

From Table 9, we see that the results between IHC and qPCR match in $85.9 \%$ of all cases. The discrepancy between the results in the remaining $14.1 \%$ of cases may be due to a lack of specificity in the IHC method, which determines the total content of all types of estrogen receptors (ER $\alpha$ and ER $\beta$ ). However, in most cases, qPCR was shown to match IHC. These results also speak in favor of the transcriptional machinery, which means that an increase in mRNA largely correlated with an increase in protein levels. A large percentage of mismatch results $(38.5 \%)$ for the PGR may indicate a more complex mechanism of regulation of the expression of this receptor. However, elucidation of this mechanism is a complex task and not the purpose of our work.

It is important to note that the proposed methodological approach allows us to discriminate between ER $\alpha$ and $\mathrm{ER} \beta$, which are difficult to differentiate using immunohistochemical analysis alone. According to the latest data, IHC may miss up to $10 \%$ of ER $\alpha+$ tumors, some of which could be caught by qPCR method [8].

Recent studies have shown that the use of qPCR is more accurate than IHC in determining the expression of steroid receptors in breast cancer cells, allowing for more accurate prognoses and the application of individual chemotherapy [9].

\section{Expression of cytokeratin 18}

In addition to examining gene expression levels of steroid receptors, we also looked at the expression of cytokeratin 18, a marker of tumor cell proliferation in patients with epithelial cell carcinoma. We found that, in both groups, there is an increase in the expression levels of the mRNA for cytokeratin 18 as the disease progresses. In the first group, mRNA expression increased from 0.41 to 0.59 as breast cancer stage increased from two to four. A similar pattern was observed for the control group: KRT 18 gene expression was increased from 0.60 to 1.14 for the 1st and 2nd stages, respectively (Table 10).

These findings are consistent with the literature, which show that an increase in KRT 18 expression levels is correlated with increasing tumor size and lymph node involvement [4]. Our results also show that the expression levels of the gene KRT 18 are 3.2 times less in the tumor tissues of patients treated with preoperative therapy (reference mRNA level - 0.41), compared with the control group (reference mRNA level - 1,14$)(p<0,05)$. These results can be explained by the fact that the expression of KRT 18 is specific to epithelial cells. As the tumors were exposed to chemotherapy, the primary tumor reached a complete morphological regression with the growth of connective tissue as fibrous component formed. This was correlated with a reduction in the expression of cytokeratins at the tumor site. Thus, KRT 18 can be considered as a surrogate marker for not only good responses to the proposed type of therapy, but also improved long-term results, such as 5 -and 10-year survival rates.

We also evaluated how the expression of cytokeratin 18depends on the tumor subtypes. We found that, in both groups, patients with ER+ breast tumors had increased levels of expression of cytokeratin (Table 11).

On average, the level of expression of cytokeratin in ER+ tumors was 2.7 times higher in comparison with ER- tumors. This is most certainly due to the fact that estrogens have a stimulatory effect on epithelial growth. Our data are consistent with the current literature that suggest that the luminal type of mammary tumors has increased expression of cytokeratin 18 compared to basal-like tumors [10].

Thus, KRT 18 can be considered as a suitable candidate marker for assessing response to chemotherapy.

\section{Conclusion}

In this work, we analyzed the gene expression levels of ERa, ER $\beta$, and PGR in two groups of patients - one treated with neoadjuvant chemotherapy, and the other, untreated. We have shown that expression levels of steroid receptors depend on the treatment method. Decreased expression of ERa in patients receiving neoadjuvant therapy appears to be associated with increased loss of epithelium and increasing fibrosis. In addition, the damaging effect of cytostatic drugs is characterized by the death of some cells and the development of metabolic disorders in others, one manifestation of which, perhaps, was the reduction in the expression of receptors for steroid hormones. Additionally, the study showed increasing levels of KRT 18 expression with increasing cancer stage and a lower level of expression of this marker in the group with NAC, which speaks in favor of the use of this marker for the assessment of therapeutic pathomorphism. We also saw increased expression of KRT 18 in ER+ tumors, which is associated with the stimulating effect estrogen, has on epithelial growth. In this work, we compared two methods used for determining steroid receptor status in breast cancer cells: IHC method, which is currently the standard in clinical practice, and $\mathrm{qPCR}$, which determines the expression of ER and PR with realtime detection. It was the coincidence of the results of these methods in more than $85 \%$ of cases that statistically proved the accuracy of qPCR. Such a high correlation between the level of ER $\alpha$ mRNA and protein content speaks in favor for a transcriptional mechanism regulating the activity of the receptor. This conclusion makes it possible to use qPCR to assess the receptor status of breast cancers.

Thus, the data obtained here can be used in the future for introducing new molecular markers of breast cancer into clinical practice, which will significantly improve approaches to the treatment of each individual patient.

\section{References}

1. Ricketts D, Turnbull L, Ryall G, Bakhshi R, Rawson NS, et al. (1991) Estrogen and progesterone receptors in the normal female breast. Cancer Res 51: 1817-1822.

2. Roger P1, Sahla ME, Mäkelä S, Gustafsson JA, Baldet P, et al. (2001) Decreased expression of estrogen receptor $\beta$ protein in proliferative preinvasive mammary tumors. Cancer Res 61: 2537-2541.

3. Olofsson MH, Ueno T, Pan Y, Xu R, Cai F, et al. (2007) Cytokeratin-18 is a usefu serum biomarker for early determination of response of breast carcinomas to chemotherapy. Clin Cancer Res 11: 3198-206.

4. Meng Y, Wu Z, Yin X, Zhao Y, Chen M, et al. (2009) Keratin 18 attenuates estrogen receptor alpha-mediated signaling by sequestering LRP16 in cytoplasm. BMC Cell Biol 10: 96.

5. Demiray M, Ulukaya EE, Arslan M, Gokgoz S, Saraydaroglu O, et al. (2006) Response to neoadjuvant chemotherapy in breast cancer could be predictable by measuring a novel serum apoptosis product, caspase-cleaved cytokeratin 18. Cancer Invest 24: 669-676.

6. Omoto $\mathrm{Y}$, Inoue S, Ogawa S, Toyama T, Yamashita H, et al. (2001) Clinica value of the wild-type estrogen receptor beta expression in breast cancer. Cancer Lett 163: 207-212 
Citation: Chernyy VS, Gulyaeva LF, Kozlov VV (2015) Expression of Steroid Receptors and Cytokeratin 18 in Breast Cancer after Neoadjuvant Chemotherapy. J Mol Biomark Diagn S2:013. doi:10.4172/2155-9929.S2-013

7. Järvinen TA, Pelto-Huikko M, Holli K, Isola J (2000) Estrogen receptor beta is coexpressed with ERalpha and PR and associated with nodal status, grade and proliferation rate in breast cancer. Am J Pathol 156: 29-35.

8. Iwamoto T, Booser D, Valero V, Murray JL, Koenig K, et al. (2012) Estrogen receptor $(E R)$ mRNA and ER-related gene expression in breast cancer that are $1 \%$ to $10 \%$ ER-positive by immunohistochemistry J Clin Oncol 30: 729-734.
9. Du X, Li XQ, Li L, Xu YY, Feng YM (2013) The detection of ESR1/PGR/ERBB2 mRNA levels by RT-QPCR: a better approach for subtyping breast cancer and predicting prognosis.Breast Cancer Res Treat 138: 59-67.

10. Walker LC, Harris GC, Holloway AJ, McKenzie GW, Wells JE, et al. (2007) Cytokeratin KRT8/18 expression differentiates distinct subtypes of grade 3 invasive ductal carcinoma of the breast.Cancer Genet Cytogenet 178: 94-103.

This article was originally published in a special issue, Cancer Biomarkers handled by Editor(s). Dr. Sudhir Srivastava, Cancer Biomarkers Research Group, National Institute of Health, USA; Dr. Shou-Jiang Gao, The University of Texas Health Science Centre at San Antonio, USA; Dr. Kenneth Maiese, University of Medicine \& Dentistry of New Jersey, New Jersey Medical School, USA 